lations. Assessment at 3 to 4 years would determine whether genetic analysis at early stage is reliable.

If found reliable, genetic assessment for other populations could also be carried out with suitable correlation factors or the extent of the relationship can be determined. In the present study, clones $8,9,16,17,37,39$ and 106 were the best performers for all traits. Their superiority, however, needs to be tested over period of time to make suitable recommendations. On the basis of mean height at the age of 24 months, thirty-two of seventy clones were taller than the mean height $(369 \mathrm{~cm})$. A total of $38 \%$ of the clones from geographical locations in Lanka were found to be above average mean height followed by Cooch Behar (22\%) and Medo (13\%). This reflects superiority of selections from Lanka over other geographical locations.

The top twenty clones in terms of mean height were assessed for their ranking at the age of 12 (May 2001), 18 (December 2001) and 24 (August 2002) months (Table 4). Clone 106 maintained $1^{\text {st }}$ rank over the period. Clones 9, 17 and 79 showed a upward trend whereas clones $3,7,11,16,27,39$ and 101 showed a decreasing trend. Though average increment for these 20 selected clones from May 2001 to August 2002 was $190 \%$, clones 79,17 and 9 showed an increment of 242, 230 and $227 \%$, respectively. The results are clear indications that testing of clones needs to be carried out for longer durations so that elite genotypes are identified and deployed thorough plantations programmes. It is also necessary to examine the trend of all the clones over the years and to group different clones for various end uses. The rapid growing clones may well be used to establish biomass plantations for paper industry whereas slower growing clones may be recommended for timber and furniture industry. However, individual clones needs to be analysed for different wood properties before recommending their deployment through plantations programmes. Nonetheless, described results indicate clonal behaviour only for height at one single location and needs to be tested for real superiority per se at different locations.

\section{Acknowledgement}

Authors are thankful to the Director, Rain Forest Research Institute, Jorhat for his continuous encouragement and support. Thanks are also due to World BankForestry Research Education \& Extension Project for financial support.

\section{References}

ANON (1991): Forestry statistics today for tomorrow. Wood and wood products 1961-1989: 2010. Food and Agriculture Organization of the United Nations, Rome.

BurTon, G. W. (1952): Quantitative inheritance in grass. In: $6^{\text {th }}$ International Grassland Congress, Part I: 277-283.

Burton, G. W. and E. H. Devane (1953): Estimating heritability in tall fecue (Festuca arundinaceae) from replicated clonal material. Agron. J. 45: 478-481.

Foster, G. S. and D. V. SHAW (1988): Using clonal replicates to explore genetic variation in a perennial plant species. Theor. Appl. Genet. 76: 788-794.

Johnson, H. K., H. F. RABInson and R. E. Comstock (1955): Estimates of genetic and environmental variability in soybeans. Agron. J. 47: 314-318.

Kumar, A., P. H. ChaWhaAn and A. K. Matharoo (2003): Improvement through selection of plus trees in Gmelina arborea. Journal of Tropical Forest Science 15 (3): 441-449.

LAL, P. (2000): National forest policy and raw materials: Supply by wood industries in India. Indian Forester 126 (4): 351-366

LUSH, I. L. (1949): Heritability of quantitative characters in farm animals. Heriditas. Suppl: 356-387.

Nelson, C. D. and C. G. TAuer (1987): Genetic variation in juvenile characteristics of Populus deltoides from Southern Great Plains. Silvae Genet. 36: 216-221.

Sukhatme, P. V. and V. N. AmBle (1989): Statistical Methods for Agricultural Workers. Publication and Information Division, ICAR, New Delhi. P 359.

ZoBEL, B. J. (1981): Vegetative propagation in forest management operations. In: Proc., $16^{\text {th }}$ South For. Tree Improv. Meet., Blacksburg, Virginia. pp. 149-159.

\title{
A Study of Population Variation and Inheritance in Sitka Spruce
}

\section{IV: Correlated response in the progeny population based on selection in the parental population}

\author{
By S. J. LeE ${ }^{\left.1)^{*}\right)}$, J. Woolliams ${ }^{2)}$, C. J. A. SAmuel ${ }^{1)}$ and D. C. MAlColm ${ }^{3)}$
}

(Received 22 $2^{\text {nd }}$ December 2005)

\footnotetext{
1) Forestry Research, Northern Research Station, Roslin, Midlothian, EH25 9SY, Scotland.

2) Roslin Institute, Roslin, Midlothian, EH25 9PS, Scotland.

$\left.{ }^{3}\right)$ Edinburgh University, Institute of Ecology and Resource Management, The King's Buildings, Edinburgh, EH9 3JU, Scotland.

*) Communicating author: Steve J. LeE, Tel: +44 (0) 1314456926 , Fax: +44(0) 131445 5124. E-Mail: steve.lee@forestry.gsi.gov.uk
}

\section{Summary}

This study investigated the potential benefits to a tree breeding programme of selection based on height in the original ortet population, and on diameter and wood density of grafted-ramets representing the same ortets growing in a clone bank. The trees studied were a large, randomly selected same-aged population of Sitka spruce 
(Picea sitchensis (Bong.) Carr.) individuals of known origin growing on a single site in North-West Scotland.

Estimates of correlated response indicated the value of including ortet height when adjusted for an environmental variable (in this case height above sea level), and grafted-ramet wood density and diameter in the estimation of breeding values. A selection intensity of 1 in 20 for height amongst ortets in the forest or grafted-ramets in the clone bank each gave a correlated increase in mid-rotation diameter of around $6 \%$ in the next generation. A similar selection intensity for wood density in the grafted-ramet population would give a $15 \%$ increase of wood density in the next generation.

The study indicates worthwhile gain can be achieved at the stage of plus-tree selection when moderate single tree heritability is combined with sufficiently high selection intensity.

Key words: Picea sitchensis, genetic variation, heritability, grafted-ramets, parental population, progeny testing, correlated response, selection intensity.

\section{Introduction}

Sitka spruce (Picea sitchensis (Bong.) Carr.) is the main plantation species in Great Britain and represents nearly $30 \%$ of the woodland area (FORESTRY COMMISSION, 2003). The Sitka spruce selection and breeding programme commenced in 1963 with the selection in British forests of superior individuals for height, diameter, stem straightness and branching quality (FLETCHER and FAULKNER, 1972). These selected trees were known as plus-trees and over 1800 were selected over the next 20 years. Whilst these trees were thought to be mostly of Queen Charlotte Islands origin (QCI; British Columbia, Canada) forest records were often incomplete. There is also known to be considerable variation in the performance of seed lots collected across the range of QCI (FLETCHER, 1992). A regular programme of open-pollinated half-sibling progeny tests of selected plus trees commenced in 1967 and continued until 1993 (LEE, 2001). Data have been collected from around half of the 200 progeny tests established over the 26 year period, and a breeding population now exists based on multi-trait selection for 15 year diameter, wood density and stem form (LEE, 2001). Estimates of additive variance components and narrow-sense heritability of traits measured in some of these progeny tests have previously been presented by GILL (1987) and LEE (1999).

Only if variance components are derived from an unselected population will they be free of any artificially induced bias for the selected or correlated traits. A sound breeding strategy is dependent on reliable information regarding the underlying variation and pattern of inheritance. When accurate estimates of unbiased genetic variances are available, it is possible to make realistic predictions of times and costs likely to be incurred under different breeding schemes and selection intensities using mathematical models. Ideally, a study into the variance components operating within an unselected population should be carried out prior to commencing a commercial selection and breeding programme. This is rarely possible due to the time delay involved in obtaining data from genetic tests of up to half a rotation length prior to starting a programme. Optimistically, progeny testing of an unselected population may be planned to run concurrently with the opera- tional testing and selection programme so that an existing improvement programme may have its efficiency increased or direction altered as necessary.

SAMUEL and Johnstone (1979), LeE et al. (2002a) and LEE et al. (2002b) are three papers from a series which investigates additive variance components operating within and between traits for a randomly selected population of trees planted in field trials in 1972. This population originated after cones were collected from trees representing all the dominance classes (sub-, co- and dominant) from a stand of known QCI origin. SAMUEL and JOHNSTONE (1979) published estimates of heritability for height up to the sixth year after field planting, and investigated changes in ranking of family performance. LEE et al. (2002a) investigated age:age correlations for height and diameter between two and 23 years from planting and optimal selection ages for vigour traits. LEE et al. (2002b) looked at changes of additive genetic variance with age and optimum selection ages for wood density.

This fourth paper in the series differs from the previous three in that it introduces data collected from the parental generation - the ortet in the forest and graftedramets of the ortet growing in a clonebank. The question is asked: 'To what degree does phenotypic performance in either of these parental sources correlate with estimates of breeding values derived from progeny test data, and how reliable are they as a form of early screening?'

It is often considered that breeding value estimation based on mass selection of the original ortet in the forest is imprecise for traits with low heritabilities. Measurements of grafted-ramets in a clone bank may be expected to give better estimates of true breeding value since ramets are often replicated within clone banks as opposed to the single representative of an ortet in a forest. Further more clone banks are often established on uniform sites whilst the environment between selected ortets in a forest can vary considerably. On the other hand, grafts may not grow in a standard manner due to a number of possibly interacting factors including the health of the scion and rootstock at the time of grafting and quality of the grafting operation.

The objectives of this paper are to:

(i) estimate the correlation between ortet breeding values derived from progeny tests for wood density and certain vigour traits, with data collected from ortets growing in the forest and grafted-ramets growing in a clone bank;

(ii) investigate the response in breeding value of the progeny as a result of selection for height in the ortet population, and diameter and density in the graftedramet population, thereby demonstrating at a more practical level the correlation between traits from the different genetic sources;

(iii) make recommendations regarding data collection from ortet and grafted-ramet populations in future estimation of variance components and breeding values.

\section{Materials and Methods}

\section{i. Progeny test data:}

In 1969, open-pollinated cones were collected from each of 150 randomly selected trees of known QCI origin 
growing across an 8 hectare stand of 34-year-old Sitka spruce located in South Strome forest, north-west Scotland (57 $21^{\prime}$ N, $6^{\circ} 32^{\prime}$ W; SAmuel and Johnstone, 1979). Progeny were raised in a nursery for two years prior to planting on three forest sites in 1972. One of the forest sites, which contained progeny from 125 of the 150 randomly selected trees was subjected to a detailed analysis of growth rate and wood density data collected between 1 and 23-years from planting (LEE et al., 2002a and 2002b). Test design was 7 × 7 (49) plant plots with 3 complete replications (147 trees per family). Trees were planted at $2 \mathrm{~m} \times 2 \mathrm{~m}$ spacing. Initially, only the inner 5 $\mathrm{x} 5$ trees were measured in each assessment for height or diameter; a maximum of 75 trees per family. Following a $50 \%$ chemical line-thinning after the $18^{\text {th }}$ growing season, the number of trees per assessment plot was reduced from 25 to either 12 or 13; a maximum of between 36 and 39 per family. Wood density assessment was based on X-ray densitometry techniques as described by Hughes and DE AlBuQUERQUe SARDINHA (1975) involving the random selection of 5 trees from the remaining 12 or 13 in each plot or 15 trees per family in total.

The number of open-pollinated families included in the estimation of variance components differed between the vigour and wood density traits. All 125 families were included in analysis of vigour traits (LEE et al., 2002a), but for reasons of economy associated with the costly nature of wood core extraction and X-ray densitometry, only 46 families were included in analysis of wood density traits (LEE et al., 2002b). The 46 families selected were considered to represent an unbiased sub-sample of the complete population of 125 families. Their selection was based on the principles of CAMERON and THOMPSON (1986) who hypothesised that if there is prior knowledge of a relationship between two traits, the errors attached to estimates of variance components would be minimised by selection of those individuals lying on the edge of an ellipse resulting from plotting the regression of one trait against the other. The 46 families selected were the outliers on a genetic selection ellipse (LEE et al., 2002b) based on the relationship between familymean values for 16-year stem diameter and a 17-year indirect assessment of wood density using the Pilodyn gun, involving all 125 families in test (WoOD, 1986; LEE, 1999).

The breeding goal for vigour was taken as 23-year diameter which was the oldest age at which growth rate data were collected and the optimum indirect selection trait was estimated to be 9-year height (LEE et al., 2002a). The breeding goal for wood density was the mean wood density of annual rings 19 through to 22 from the pith (weighted by individual ring surface area; RG19-22) and the optimum indirect selection trait was the mean density of annual rings 6 through to 9 from the pith (RG6-9; LEE et al., 2002b).

Estimated variance and covariances associated with the direct and indirect breeding goals represent the progeny test data against which data from the parental generation were correlated.

\section{ii. Ortet data:}

When the parent trees were felled in 1973, total tree height was measured as the combination of stump height and felled tree length. Wood density was not assessed. The height above sea level (HASL) at which the randomly selected trees were growing ranged from $30 \mathrm{~m}$ to $130 \mathrm{~m}$. Since decline in total tree height with increase in HASL as a result of increased exposure, reduced temperatures and consequently reduced growing season, has been documented on the west coast of Scotland even for such relatively small elevation variations (WORRELL, 1987), individual ortet HASL was used as a covariate to estimate adjusted ortet heights relative to the mean HASL of all the selected trees prior to correlation with progeny test data.

\section{iii. Grafted-ramet data:}

Scions were collected from each ortet prior to felling and grafted on to juvenile Sitka spruce rootstock in 1972. Three grafted-ramets (copies) of each ortet were planted adjacent to each other in a sequential pattern within the Sitka spruce clone bank located at Ledmore, Central Region, Scotland ( $56^{\circ} 28^{\prime} \mathrm{N}, 3^{\circ} 32^{\prime} \mathrm{W}$ ) in spring 1975. Grafted-ramets were planted in an east/west direction with $2 \mathrm{~m}$ between trees within a row and $3 \mathrm{~m}$ between rows.

In November 1995, when the grafted-ramets were 21 years from planting, diameter and density assessments were carried out at breast height $(1.3 \mathrm{~m})$. Wood density was measured both indirectly, using the Pilodyn expressed as the mean of scores on the north and west side of each tree, and directly following gravimetric assessment of the outer 5 rings from an $8 \mathrm{~mm}$ core extracted with a Pressler Borer from the northern radius (pith to bark).

Measurements were restricted to those grafted-ramets of ortets representing the 46 open-pollinated families analysed for wood density in LEE et al. (2002b). Data were collected from all live ramets which did not have visible incompatibility problems. These restrictions lead to the rejection of four of the original 46 selections.

\section{Statistical Methods}

Analysis involved bringing together the data from the different genetic sources. All analyses involving progeny test data for wood density (RG19-22 and RG6-9), as measured on the reduced population of 46 families, included 17-year Pilodyn and 16-year diameter data from all 125 families as covariates (LEE et al., 2002b) and were therefore quadrivariate. All other regressions involved bivariate analysis. All data were standardised by subtracting the mean and dividing by the standard deviation for that trait.

The standard linear mixed model employed to estimate variance components and fixed effects in the progeny test for each trait was:

$$
Y_{i j k}=\mu+R_{i}+F_{i}+f_{i j}+e_{i j k}
$$

where:

$Y_{i j k}=$ observed measurement of tree $i j k$;

$\mu=$ a fixed general mean;

$R_{i}=$ fixed effect of replicate $i, i=1,2$ or 3 ;

$F_{j}=$ random effect of family $j, j=1,2,3, \ldots \ldots ., 46$, $\operatorname{Var}\left(F_{j}\right)=\sigma_{\mathrm{f}}^{2}$;

$f_{i j}=$ random effect of family $j \mathrm{x}$ replicate $i$ interaction, $\operatorname{Var}\left(f_{i j}\right)=\sigma_{\text {fr }}^{2}$; 
$e_{i j k}=$ random error of tree $k$ from family $j$ in replicate $i, \operatorname{Var}\left(e_{i j k}\right)=\sigma_{\mathrm{e}}^{2}$.

All variance components, heritabilities and associated standard errors (SE) were estimated using ASReml (spatial restricted maximum likelihood), a mixed model analysis software programme developed by GILMOUR (1996) which in turn calls upon the original concepts of REML (PATTERSON and THOMPSON, 1971).

ASReml fits the following general mixed model (GILMOUR, 1996):

$$
y=X b+Z_{1} a_{1}+Z_{2} a_{2}+e
$$

where:

$y=(n \times 1)$ vector of observations (i.e. measurements such as $Y_{i j k}$ in Equation 1);

$X=(n \times p)$ design matrix which relates each observation to the fixed effects $b$ (replicates in Equation 1);

$b=(\mathrm{p} \times 1)$ vector of fixed effects;

$Z_{1}=(n \times q)$ design matrix which relates observations to random family effects;

$a_{1}=(q \times 1)$ vector of random family effects $\left(\sigma_{\mathrm{f}}^{2}\right.$ in Equation 1);

$Z_{2}=(n \times q)$ design matrix which relates observations to random family $\mathrm{x}$ replicate interactions;

$a_{2}=(q \times 1)$ vector of random family $\mathrm{x}$ replication effects $\left(\sigma_{\text {fr }}^{2}\right.$ in Equation 1);

$e=(n \times 1)$ vector of independent random residual effects $\left(\sigma_{\mathrm{e}}^{2}\right.$ in Equation 1).

Estimates of the different variance and covariance components were further used to calculate a number of statistical functions as follows:

\section{i. Clonal heritability}

Clone-mean heritability $\left(\mathrm{H}_{\mathrm{C}}^{2}\right)$ was estimated for all grafted-ramet traits according to:

$$
H_{\mathrm{C}}^{2}=\frac{\sigma_{\mathrm{G}}^{2}}{\sigma_{\mathrm{G}}^{2}+\sigma_{\mathrm{G}(\mathrm{n})}^{2}}
$$

where:

$\sigma_{\mathrm{G}}^{2} \quad$ = variance between clones;

$\sigma_{G(n)}^{2}=$ variance due to clone $\mathrm{x}$ grafted-ramet interaction, with $\mathrm{n}$ grafted-ramets representing an ortet.

\section{ii. Simple correlation coefficients}

The simple correlation $(r)$ between ortet height or grafted-ramet mean value, with progeny-mean values were estimated according to:

$$
r=\frac{\operatorname{COV}_{\bar{X}} \bar{Y}}{\sqrt{\sigma \frac{2}{X} \sigma \frac{2}{Y}}}
$$

where:

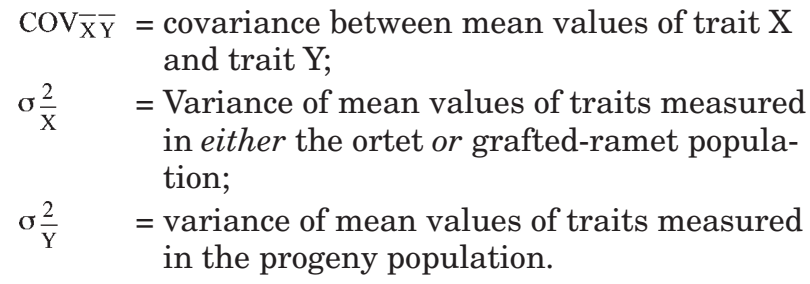

\section{iii. Genetic correlations}

Genetic correlations $\left(\mathrm{r}_{\mathrm{g}, \mathrm{BV}}\right)$ were only an approximation as they involved correlating the genotypic values (additive and non-additive) of the clonal data with the breeding values (additive only) of traits derived from the progeny test as follows:

$$
r_{\mathrm{g}, \mathrm{BV}}=\frac{\operatorname{COV}_{\mathrm{G}_{\mathrm{XY}}}}{\sqrt{\sigma_{\mathrm{GX}}^{2} \sigma_{\mathrm{GY}}^{2}}}
$$

where:

$\mathrm{COV}_{\mathrm{G}}=$ genetic covariance between traits measured in the ortet or grafted-ramet populations with traits measured in the progeny population;

$\sigma^{2}{ }_{G_{Y}}=$ genetic variance of trait measured in the progeny population;

$\sigma^{2}{ }_{G_{X}} \quad=$ genetic variance of trait measured in the ortet or grafted-ramet population.

The model assumes that non-additive genetic variance is zero.

Since $\sigma^{2}{ }_{G X}$ could not be estimated for ortet height, the phenotypic variance was substituted and weighted by the same value of single tree heritability $\left(\mathrm{h}^{2}{ }_{\mathrm{i}}=0.15\right)$ used to calculate $\left(\mathrm{r}_{\mathrm{g}, \mathrm{BV}}\right)$ as reported in LEE (2001).

In most cases, correlations were only attempted between genetic sources for closely related traits; for example vigour assessment in the ortet or grafted-ramet populations with vigour assessments in the progeny population, or density assessments in the grafted-ramet population with density assessments in the progeny population. The only exception to this was an attempt to correlate grafted-ramet wood density with DM23 (the breeding goal) in the progeny population. This lone cross-trait correlation was carried out due to some expectation of success based on the relatively high genetic correlations previously found between wood density and vigour traits (LEE et al., 2002b) and a desire to investigate the indirect effect of selection for one trait on another in the next generation.

\section{iv. Correlated response}

The correlated response of breeding values in the progeny population (Y) following selection for a specific trait within the ortet or grafted-ramet population $(\mathrm{X})$ is a function of the regression coefficient between the two traits $\left(b_{\mathrm{YX}}\right)$, the selection differential of trait $\mathrm{X}$ and the mean value of trait $\mathrm{Y}$ as follows:

$$
\begin{aligned}
& \text { Correlated response in Trait Y } \\
& =\mathrm{b}_{\mathrm{xy}} \frac{(\text { selection differential for Trait X) }}{\left(\text { Trait } \mathrm{X}_{\text {mean }}\right)} \times 100 \%
\end{aligned}
$$

where byx, $=\frac{\text { COVG }_{X Y}}{\sigma^{2} P_{X}}$

and $\sigma^{2}{ }_{\mathrm{PX}}=$ phenotypic variance of a trait measured in the ortet or grafted-ramet population (X).

\section{Results}

Trait-mean values, standard deviations and number of treatments (families, ortets or ortets represented by 
grafted-ramets) associated with each of the data-sources are given in Table 1.

Estimates of phenotypic variance $\sigma_{P}^{2}$, genotypic variance $\left(\sigma_{G}^{2}\right)$ and clonal or family mean variance $\left(\sigma^{2}{ }_{C}\right.$ and $\sigma_{f}^{2}$ ) are given in Table 2. Estimates of phenotypic covariance between treatment means $\left(\mathrm{COV}_{\mathrm{XY}}\right)$ and genetic covariance $\left(\mathrm{COV}_{\mathrm{G}_{\mathrm{XY}}}\right)$ between traits measured in the progeny population $(\mathrm{Y})$ and the ortet and grafted-ramet populations (X) are presented in Table 3. Data for RG1922 are omitted since convergence in ASReml was not achieved. The RG19-22 trait was omitted from all further correlation with other traits in the ortet or graftedramet populations. Convergence was successfully achieved between the indirect selection goal for wood density (RG6-9) in the progeny population and density from assessments carried out in the grafted-ramet population.

Estimates of clonal heritability for traits measured on the grafted-ramets are given in Table 4. Direct assessment of wood density gave a lower clonal-heritability value than indirect (Pilodyn) which is surprising, although the respective standard errors gives considerable overlap between these two methods of density assessment.

Estimates of $\mathrm{r}$ and $\left(\mathrm{r}_{\mathrm{g}, \mathrm{BV}}\right)$ are given in Table 5. On each occasion $\left(\mathrm{r}_{\mathrm{g}, \mathrm{BV}}\right)$ exceeds $\mathrm{r}$, particularly so for ortet height with progeny DM23 and HT09. This probably reflects the errors associated with introducing an assumed value of individual tree heritability for mature height of $\mathrm{h}^{2}{ }_{\mathrm{i}}=$ 0.15 .

Table 1. - Mean value, standard deviations and number of treatments according to genetic source and trait.

\begin{tabular}{|c|c|c|c|c|}
\hline Source & Trait & Mean & $\begin{array}{l}\text { Standard } \\
\text { Deviation (+/-) }\end{array}$ & $\begin{array}{l}\text { Number of } \\
\text { Treatments }\end{array}$ \\
\hline Progeny: & $\begin{array}{l}\text { HT09 }(\mathrm{cm}) \\
\text { DM23 }(\mathrm{cm}) \\
\text { RG6-9 }(\mathrm{g} \mathrm{cm}) \\
\text { RG19-22 }\left(\mathrm{g} \mathrm{cm}^{-3}\right)\end{array}$ & \begin{tabular}{|l}
359.64 \\
15.08 \\
0.5121 \\
0.4781
\end{tabular} & $\begin{array}{r}75.1060 \\
3.4022 \\
0.0659 \\
0.0546\end{array}$ & $\begin{array}{r}125 \\
125 \\
46 \\
46\end{array}$ \\
\hline Ortets: & Adjusted Height (m) & 22.83 & 2.6880 & 125 \\
\hline Grafted-ramets: & $\begin{array}{l}\text { Diameter }(\mathrm{cm}) \\
\text { Pilodyn }(\mathrm{mm}) \\
\text { Density }\left(\mathrm{g} \mathrm{cm}^{-3}\right)\end{array}$ & $\begin{array}{l}17.57 \\
18.44 \\
0.3416\end{array}$ & $\begin{array}{l}4.2151 \\
2.7769 \\
0.0363\end{array}$ & $\begin{array}{l}42 \\
42 \\
42\end{array}$ \\
\hline
\end{tabular}

Note: Number of trees per treatment varies as follows: 25 per plot equivalent to 75 per family (HT09); 12 or 13 per plot equivalent to a mean of 37.5 per family (DM23); 5 per plot equivalent to 15 per family (RG6-9 and RG19-22); 3 per plot for all graftedramet measurements. All assessments carried out on the grafted-ramet population 21 years after planting.

Table 2. - Phenotypic, genotypic and treatment-mean (clonal or family) variance components according to trait and genetic sources (ortet, grafted-ramets or progeny).

\begin{tabular}{|c|c|c|c|c|}
\hline Source & Trait & $\begin{array}{c}\text { Phenotypic Variance } \\
\sigma_{\mathrm{P}}^{2}\end{array}$ & $\begin{array}{c}\text { Genotypic Variance } \\
\sigma_{G}^{2}\end{array}$ & $\begin{array}{l}\text { Clonal or } \\
\text { Family mean } \\
\text { Variance } \\
\sigma_{c}^{2} \text { or } \sigma_{f}^{2}\end{array}$ \\
\hline ORTET & Height (m) & $\begin{array}{l}7.2250 \\
(0.72)\end{array}$ & $\mathrm{N} / \mathrm{A}$ & $\begin{array}{r}7.2250 \\
(0.72)\end{array}$ \\
\hline \multirow{3}{*}{$\begin{array}{l}\text { GRAFTED } \\
\text { RAMET }\end{array}$} & Diameter (mm) & $\begin{array}{c}1812.24 \\
(44.98)\end{array}$ & $\begin{array}{l}970.62 \\
(275.0)\end{array}$ & $\begin{array}{l}1216.7 \\
(41.22)\end{array}$ \\
\hline & Density $\left(\mathrm{g} \mathrm{cm}^{-3}\right)$ & $\begin{array}{c}0.1262 \times 10^{-2} \\
\left(0.21 \times 10^{-3}\right)\end{array}$ & $\begin{array}{l}0.6940 \times 10^{-3} \\
\left(0.21 \times 10^{-3}\right)\end{array}$ & $\begin{array}{r}0.7390 \times 10^{-3} \\
\left(0.2014 \times 10^{-3}\right)\end{array}$ \\
\hline & Pilodyn (mm) & $\begin{array}{c}7.5585 \\
(1.32)\end{array}$ & $\begin{array}{l}4.6807 \\
(1.30)\end{array}$ & $\begin{array}{l}4.8087 \\
(1.28)\end{array}$ \\
\hline \multirow{3}{*}{ PROGENY } & DM23 (cm) & $\begin{array}{c}11.3180 \\
(0.25)\end{array}$ & $\begin{array}{l}1.6610 \\
(0.39)\end{array}$ & $\begin{array}{c}0.5733 \\
\left(0.94 \times 10^{-1}\right)\end{array}$ \\
\hline & HT09 (cm) & $\begin{array}{l}5372.4 \\
(145.2)\end{array}$ & $\begin{array}{l}1862.7 \\
(471.0)\end{array}$ & $\begin{array}{c}879.98 \\
(112.07)\end{array}$ \\
\hline & RG6-9 $\left(\mathrm{g} \mathrm{cm}^{-3}\right)$ & $\begin{array}{l}0.4134 \times 10^{-2} \\
\left(0.34 \times 10^{-3}\right)\end{array}$ & $\begin{array}{l}0.3388 \times 10^{-2} \\
\left(0.10 \times 10^{-2}\right)\end{array}$ & $\begin{array}{l}0.1214 \times 10^{-2} \\
\left(0.96 \times 10^{-4}\right)\end{array}$ \\
\hline
\end{tabular}

Note: Ortet clonal variance equates to phenotypic variance since $n=1$; Standard Errors in parentheses. 
Table 3. - Estimated covariance between treatment means and genotypic covariance between ortet or grafted-ramet traits (X) and selected, progeny-based traits (Y).

\begin{tabular}{|c|c|c|c|c|c|c|c|}
\hline & & \multicolumn{6}{|c|}{ TRAITS MEASURED ON PROGENY } \\
\hline & & \multicolumn{3}{|c|}{ Covariance - $\mathrm{COV}_{\mathrm{XY}}$} & \multicolumn{3}{|c|}{ Genetypic covariance $-\mathrm{COV}_{\mathrm{G}_{\mathrm{xr}}}$} \\
\hline & & $\begin{array}{c}\text { DM23 } \\
\text { (cm) }\end{array}$ & $\begin{array}{l}\text { HT09 } \\
\text { (cm) }\end{array}$ & $\begin{array}{r}\text { RG6-9 } \\
\left(\mathrm{g} \mathrm{cm}^{-3}\right)\end{array}$ & $\begin{array}{l}\text { DM23 } \\
\text { (cm) }\end{array}$ & $\begin{array}{l}\text { HT09 } \\
\text { (cm) }\end{array}$ & $\begin{array}{l}\text { RG6-9 } \\
\left(\mathrm{g} \mathrm{cm}^{-3}\right)\end{array}$ \\
\hline ORTET & $\begin{array}{l}\text { Height } \\
\text { (m) }\end{array}$ & $\begin{array}{c}0.64 \\
(0.21)\end{array}$ & $\begin{array}{l}20.92 \\
(7.20)\end{array}$ & & $\begin{array}{l}1.28 \\
(0.41)\end{array}$ & $\begin{array}{c}41.81 \\
(14.39)\end{array}$ & \\
\hline \multirow{3}{*}{$\begin{array}{l}\text { GRAFTED } \\
\text { RAMET }\end{array}$} & $\begin{array}{l}\text { Diameter } \\
(\mathrm{mm})\end{array}$ & $\begin{array}{c}6.41 \\
(3.91)\end{array}$ & $\begin{array}{c}106.5 \\
(148.08)\end{array}$ & & $\begin{array}{l}12.82 \\
(7.81)\end{array}$ & $\begin{array}{l}212.96 \\
(296.13)\end{array}$ & \\
\hline & $\begin{array}{l}\text { Density } \\
\left(\mathrm{g} \mathrm{cm}^{-3}\right)\end{array}$ & $\begin{array}{l}-0.78 \times 10^{-2} \\
\left(0.35 \times 10^{-2}\right) \\
\end{array}$ & & $\begin{array}{c}0.40 \times 10^{-3} \\
\left(0.59 \times 10^{-4}\right) \\
\end{array}$ & $\begin{array}{l}-0.16 \times 10^{-1} \\
\left(0.17 \times 10^{-1}\right) \\
\end{array}$ & & $\begin{array}{r}0.79 \times 10^{-3} \\
\left(0.30 \times 10^{-3}\right) \\
\end{array}$ \\
\hline & $\begin{array}{l}\text { Pilodyn } \\
\text { (mm) }\end{array}$ & $\begin{array}{c}0.42 \\
(0.29)\end{array}$ & & $\begin{array}{l}-0.20 \times 10^{-1} \\
\left(0.12 \times 10^{-1}\right)\end{array}$ & $\begin{array}{c}0.85 \\
(0.56)\end{array}$ & & $\begin{array}{l}-0.40 \times 10^{-1} \\
\left(0.23 \times 10^{-1}\right)\end{array}$ \\
\hline
\end{tabular}

Table 4. - Grafted-ramet clone-mean heritabilities $\left(\mathrm{H}_{\mathrm{C}}^{2}\right)$.

\begin{tabular}{||c|c|c|c||}
\hline \hline Grafted-ramet trait & $\underset{G}{\sigma^{2}}$ & $\underset{G(n)}{\sigma^{2}}$ & $\mathrm{H}_{\mathrm{C}}^{2}$ \\
\hline Diameter & 935.26 & 843.14 & $0.53(0.09)$ \\
\hline Density & $0.6940 \times 10^{-3}$ & $0.5676 \times 10^{-3}$ & $0.55(0.09)$ \\
\hline Pilodyn & 4.6807 & 2.8786 & $0.62(0.08)$ \\
\hline
\end{tabular}

Table 5. - Treatment-mean correlations ( $\mathrm{r}$ ) and genetic correlations $\left(\mathrm{r}_{\mathrm{g}, \mathrm{BV}}\right)$ between ortet or grafted-ramets traits, with progeny traits.

\begin{tabular}{|c|c|c|c|c|c|}
\hline & & & \multicolumn{3}{|c|}{ PROGENY } \\
\hline & & & $\begin{array}{l}\text { DM23 } \\
\text { (cm) }\end{array}$ & $\begin{array}{l}\text { HT09 } \\
\text { (cm) }\end{array}$ & $\begin{array}{c}\text { RG6-9 } \\
\left(\mathrm{g} \mathrm{cm}^{-3}\right)\end{array}$ \\
\hline \multirow{2}{*}{ ORTET } & \multirow{2}{*}{ Height } & $r$ & $0.32(0.09)$ & $0.26(0.08)$ & \\
\hline & & $\mathrm{rg}, \mathrm{BV}$ & $0.95(0.28)$ & $0.93(0.29)$ & \\
\hline \multirow{6}{*}{$\begin{array}{l}\text { GRAFTED } \\
\text { RAMET }\end{array}$} & \multirow{2}{*}{ Diameter } & $r$ & $0.24(0.14)$ & $0.10(0.14)$ & \\
\hline & & $\mathrm{rg}, \mathrm{BV}$ & $0.33(0.19)$ & $0.16(0.12)$ & \\
\hline & \multirow{2}{*}{ Density } & $r$ & $-0.34(0.14)$ & & $0.42(0.13)$ \\
\hline & & $r_{g, B V}$ & $-0.45(0.19)$ & & $0.58(0.18)$ \\
\hline & \multirow{2}{*}{ Pilodyn } & $r$ & $0.24(0.15)$ & & $-0.26(0.14)$ \\
\hline & & $\mathrm{rg}_{\mathrm{g}, \mathrm{BV}}$ & $0.30(0.19)$ & & $-0.35(0.19)$ \\
\hline
\end{tabular}

Note: A single tree heritability $\left(\mathrm{h}_{\mathrm{i}}^{2}\right)$ of 0.15 was assumed for ortet height (LEE, 2001).

Values of $\mathrm{r}$ and $\left(\mathrm{r}_{\mathrm{g}, \mathrm{BV}}\right)$ involving grafted-ramet diameter with progeny DM23, HT09 and grafted-ramet Pilodyn with RG6-9 were very low, indicating no benefit from including these grafted-ramet traits in the estimation of ortet breeding values. In contrast, values of $r$ and $\left(\mathrm{r}_{\mathrm{g}, \mathrm{BV}}\right)$ for grafted-ramet density and progeny RG6-9 were quite large.

The largest value of correlated response (Table 6) was grafted-ramet density with RG6-9 (15\%); followed by grafted-ramet Pilodyn with RG6-9 (9.0\%) and ortet height with HT09 (9.0\%). The correlated (negative) response between grafted-ramet density and DM23 was also high $(-8.5 \%)$ indicating the high genetic correlation between these two contrasting traits (LEE et al., 2002b).

\section{Discussion}

\section{i. Ortet Height}

Despite relatively low values of simple treatmentmean correlations $(r)$, genetic correlations $\left(r_{g, B V}\right)$ were 
Table 6. - Regression coefficients $\left(\mathrm{b}_{\mathrm{YX}}\right)$ between the breeding value of certain traits in the progeny population with genotypic values in the ortet and grafted-ramet population, and the correlated response in the progeny trait following a $5 \%$ selection intensity amongst the ortet or grafted-ramet population.

\begin{tabular}{|c|c|c|c|c|}
\hline & & \multicolumn{3}{|c|}{ PROGENY } \\
\hline & & DM23 & HT09 & RG6-9 \\
\hline ORTET & $\begin{array}{c}\text { Height: } \\
\text { b }_{Y X} \\
5 \%\end{array}$ & $\begin{array}{c}0.17 \mathrm{~cm} / \mathrm{m} \quad(0.05) \\
6.2 \%\end{array}$ & $\begin{array}{c}5.83 \mathrm{~cm} / \mathrm{m}(2.3) \\
9.0 \%\end{array}$ & \\
\hline \multirow{3}{*}{$\begin{array}{l}\text { GRAFTED } \\
\text { RAMET }\end{array}$} & $\begin{array}{c}\text { Diameter: } \\
b_{Y X} \\
5 \%\end{array}$ & $\begin{array}{c}0.011 \times 10^{-1} \mathrm{~cm} / \mathrm{mm}(0.62) \\
6.0 \%\end{array}$ & $\begin{array}{c}0.17 \mathrm{~cm} / \mathrm{mm}(0.23) \\
4.0 \%\end{array}$ & \\
\hline & \begin{tabular}{|c|} 
Density: \\
$b_{Y X}$ \\
$5 \%$ \\
\end{tabular} & $\begin{array}{c}-17.50 \mathrm{~cm} / \mathrm{g} \mathrm{cm}^{-3}(7.1) \\
-8.5 \%\end{array}$ & & $\begin{array}{c}1.07 \mathrm{~g} \mathrm{~cm}^{-3} / \mathrm{g} \mathrm{cm}^{-3}(0.37) \\
15 \%\end{array}$ \\
\hline & $\begin{array}{c}\text { Pilodyn: } \\
b_{Y X} \\
5 \%\end{array}$ & $\begin{array}{c}0.15 \mathrm{~cm} / \mathrm{mm}\left(0.97 \times 10^{-1}\right) \\
5.4 \%\end{array}$ & & $\begin{array}{c}-0.0083 \mathrm{~g} \mathrm{~cm}^{-3} / \mathrm{mm}\left(0.47 \times 10^{-2}\right) \\
9 \%\end{array}$ \\
\hline
\end{tabular}

Note: The value of $b_{\mathrm{YX}}$ indicates the unit increase in the progeny trait following a unit increase in selection intensity for the trait in the ortet or grafted-ramet population. 5\% selection intensity ( 7 trees out of $150 ; \mathrm{i}=2.060$; BECKER, 1984) indicates the increase in breeding value in the progeny population as a result of selecting the best $5 \%$ of trees in the ortet or graftet-ramet population.

high between adjusted ortet height and the direct (DM23) and indirect (HT09) breeding goals from the progeny test data. The absolute values of $\left(r_{\mathrm{g}, \mathrm{BV}}\right)$ were undoubtedly dependent on the assumed single tree heritability for mature tree height, but it does at least reflect a strong general relationship between adjusted tree height and progeny breeding goals for diameter.

There are many factors which can influence the growth rates of trees across a site or forest. HASL was considered to be the most restrictive factor in this population of ortets, at other sites it may be one or more other independent or interacting variables. From this study it would appear that provided the height of ortets is adjusted according to a measurable and well correlated site variable or variables it would be worthwhile combining ortet height along with vigour data from progeny tests when estimating breeding values.

Estimates of the correlated response $\left(b_{\mathrm{YX}}\right)$ are independent of the assumptions regarding single tree heritability for mature tree heights. Data presented in Table 6 indicate that a relatively large selection intensity $(5 \%$; 1 in 20) based on adjusted height at the time of plus tree (ortet) selection will result in a worthwhile increase in early height $(\mathrm{HT} 09 ;+9 \%)$ and later stem diameter (DM23; +6.2\%) breeding values relative to a random selection. These finding are in contrast to those made by Samuel and Johnstone (1979) following analysis of early height data involving the same ortet and progeny population. Samuel and Johnstone (op cit) did not include any adjustment according to an environmental covariate in their analysis and cast great doubt on the potential gains from a system of selecting superior phenotypes in the forest. They concluded that a 5\% (1 in 20) selection intensity in the forest would have given modest gains of around $1.4 \%$ for open-pollinated seed, doubling to $2.8 \%$ in an untested clonal seed orchard. As a result of such conclusions, the selection intensity of plus-trees was much reduced in the British Sitka spruce breeding pro- gramme, with a greater emphasis being placed on reselection of genotypes based on actual progeny performance.

Some years later, ConELIUS (1994) in a comprehensive review of the plus-tree literature, found that genetic gains of up to $15 \%$ in height and $35 \%$ in volume can be achieved providing selection intensities are high (around 1 in 1,000) combined with moderate heritability (0.2). Furthermore, simulation studies by DANUSEVIČIUS and LINDGREN (2002) found phenotypic selection to be the most efficient (in terms of genetic gain per year within a given annual budget) if single tree heritability exceeds 0.4 , and was only slightly inferior to progeny testing at lower heritabilities. With hindsight, a more cost effect way to select superior genotypes in the Sitka spruce breeding programme in Britain, would have been to continue with a very high selection differential of ortets combined with an adjustment for a reliable environmental variable, or only select plus-trees on relatively uniform sites where heritability would tend to be higher.

\section{ii. Grafted-ramets}

It is interesting that the mean wood density data of rings 19 to 22 (RG19-22) did not converge when correlated with grafted-ramet density data, where-as the equivalent for rings 6 to 9 (RG6-9) did converge. It becomes more difficult to achieve convergence as the number of variables and levels of analysis increases (HILL and ThOMPSON, 1978) and the quadrivariate analysis carried out here meant the software and genetic theory were possibly operating at the extremes of their capabilities. High genetic correlation between traits can exacerbate the problem particularly if the number of trees representing some of the traits becomes very small with great imbalance between traits, as is the case here. It is possible that the genetic correlation between RG19-22 with grafted-ramet density and Pilodyn may be even greater 
than it was for RG6-9 and other sample-size limitations combined to prevent covergence.

Grafted-ramet wood density and wood density of rings 6 to 9 from planting (RG6-9) in the progeny population gave the largest genetic correlation $\left(r_{g, B V}=0.58\right)$ of all combinations investigated. These two traits also gave the highest percentage correlated response of breeding values in the progeny population following selection of the best $5 \%$ of trees in the parental generation $\left(\mathrm{b}_{\mathrm{YX}}=\right.$ 15\%; Table 6). The evidence seems clear that in those situations where a grafted-ramet population exists and is growing on a relatively uniform environment such as most clone banks, screening the grafts for wood density (either directly or indirectly using the Pilodyn gun) would assist in the selection of high-density genotypes and rejection of low-density genotypes.

There was a moderate negative genetic correlation between grafted-ramet density and progeny diameter at age 23-years (DM23; $\mathrm{r}_{\mathrm{g}, \mathrm{BV}}=-0.45 ;$ Table 5). In addition, the correlated response in DM23 was greater following a $5 \%$ selection intensity based on grafted-ramet density $(-8.5 \%)$ than the same selection intensity for ortet height (6.2\%; Table 6). Simple treatment-mean correlations were also larger between grafted-ramet density and DM23 $(r=-0.45)$ than between ortet height and DM23 $(r=0.32)$. The extra correlated response despite the cross-trait correlation are interesting and probably reflects the generally higher levels of heritability associated with wood density in Sitka spruce (LEE et al., $2002 \mathrm{~b}$ ). The general findings are that screening based on grafted-ramet wood density would be successful in improving the mean breeding value of subsequent generations, and would assist in the estimation of diameter breeding values when included in bivariate analysis linking the pedigree of the parent and progeny generations.

The clonal heritability of grafted-ramet wood density $\left(\mathrm{H}^{2}{ }_{\mathrm{C}}=0.55\right.$; Table 4) is larger than the single tree heritability $\left(\mathrm{h}^{2}{ }_{\mathrm{i}}=0.33\right)$ for similar aged ring-groupings found in the progeny test population (LEE et al., 2002b). This suggests a large proportion of non-additive genetic variance operating within the species for wood density which breeders could exploit when selecting the best individuals within families.

\section{iii. Data from alternative sources}

Progeny tests remain the most reliable source of breeding value estimation. Whilst data from neither ortet or grafted-ramet populations would replace progeny tests, they could prove useful by increasing the accuracy of estimated breeding values relative to progeny tests alone. When the opportunity arises, prior screening of an ortet (height) or grafted-ramet population (diameter or density) could have the effect of reducing the number of parental trees subjected to subsequent progeny testing so reducing the size and cost of such tests.

Published literature on the relationship between either grafted ramets and ortets, or grafted-ramets and progeny is scarce and sometimes conflicting. No other study was found which investigated the relationship between all three genetic levels; ortet, grafted ramets and progeny. Some studies have been made to compared either ortets with progeny, or ortets with grafted ramets for a limited number of species. In two of the most comprehensive studies, ERICSON (1960) found significant correlations between the relative basic wood density of 61 Scots pine (SP; Pinus sylvestris L.) and 15 Norway spruce (NS; Picea abies (L.) Karst) parent trees growing in native forests in Sweden, with the relative basic density of their respective 12-year-old grafts growing in clone banks (SP r = 0.80; NS r = 0.76). GISLERUD (1973), in a similar study involving 49 Norway spruce plus-trees and 6 to 13-year-old grafted-replicates of the same trees, found a working relationship $(r=0.51)$ between these two sources for relative wood density. In all three of these studies, basic wood density was adjusted to relative wood density following corrections based on functions of growth rate (ring-width) and heat-sum between June and August. In another Scandinavian study, RUDEBJER (1984) found a simple correlation coefficient of $r=$ 0.57 between the wood density of rings laid down in Scots pine ortets and those laid down in the same calendar years in grafted ramets of those same ortets growing in a clone bank. This was in contrast to an unfavourable correlation $(r=0.14)$ comparing the wood density of rings laid down when ortet and grafted-ramet were of a similar size.

ZoBEL et al. (1962), found no significant relationship $(\mathrm{r}=0.28)$ for basic wood density in slash pine (Pinus elliottii Engelm. var elliottii) between ortets and grafted ramets. There are a number of possible explanations for this variance relative to the Scandinavian studies including a small sample size (33 clones) and young grafts (3-years-old). Most importantly, unlike ERICSON (1960) and Gislerud (1973), there was no attempt to remove possible effects of the widely varied environments encountered by the parent trees in the slash pine study. NiCHOLLS and BROWN (1971) investigated the relationship between 20 radiata pine (Pinus radiata D. Don) ortets and ramets for wood density. The ortets were derived from three different plantations in New South Wales, Australia and again there was no attempt to remove environmental variables either between or within sites despite reported variations in HASL at the ortet location of nearly $250 \mathrm{~m}$. Although there was no significant linear relationship for average density at this (unadjusted) sub-population level, NICHOLLS and BROwN (op cit.) did find the top ranking ortet for density was also the top-ranking ramet and the least dense ortet was also the least dense ramets.

The results from this study suggest that breeders could consider combining grafted-ramet density with progeny test data when estimating breeding values and variance components for wood density and diameter selection goals. In addition, ortet height, adjusted according to well correlated site variables, could be a useful addition to estimating diameter breeding values. Further benefit would derive from use of the graftedramet data if each individual graft was planted randomly in a complete block design within the clone bank, as is the practise in clonal seed orchards, so minimising possible environment by genotype interaction across the grafted-ramet site.

It is likely to be rare that breeders can take advantage of the association between breeding value estimates from progeny tests and assessments of grafted-ramets since the latter are often created either at the same time 
as progeny tests, or even after screening based on assessments carried out in progeny test. This study does suggest that breeders could make more use of basic data from ortets if they collect well-correlated environmental data which can act as covariates to adjust raw growth rate data, and were to employ a high selection intensity amongst the adjusted data.

\section{Conclusions}

This study found high genetic correlations between genotypic values of grafted-ramet density assessed in a clone bank and breeding values of juvenile wood density and mid-rotation diameter assessed in a progeny test. In addition, breeders may wish to consider including data of adjusted ortet height when estimating height and diameter breeding values based primarily on progeny test data.

The study has shown that data collected from graftedramets growing in clone banks may be worthwhile when estimating the genetic value of selected trees. It has also demonstrated the extra gain available in the progeny generation following high selection intensity in the parent population compared to random tree selection. This justifies the idea of selecting the best phenotypes in the parental population when heritability is moderate, providing the selection intensity is high and an effort is made to remove environmental variation across the site.

\section{Acknowledgements}

The authors would like to thank Dr. T. ConNolLy, Statistician with Forest Research for helpful comments made on an early draft of this paper, members of the Forest Research Technical Support Unit for collection of increment cores from the grafted-ramets and past members of the then Genetics Branch for collection of site and plustree data from South Strome forest.

\section{References}

BECKER, W. A. (1984): Manual of Quantitative Genetics. Academic Enterprises, Pulman, WA, USA. 190pp.

Cameron, N. D. and R. Thompson (1986): Design of multivariate selection experiments to estimate genetic parameters. Theoretical and Applied Genetics 72, 466-476.

CoRnelius, J. (1994): The effectiveness of plus-tree selection for yield. Forest Ecology and Management. 67, 23-34.

DANUSEVIC̆IUS, D. and D. LINDGREN (2002): Efficiency of selection based on phenotype, clone and progeny testing in long-term breeding. Silvae Genetica Vol. 51 (1): 19-26.

ERICSON, B. (1960): Studies of the genetical wood density variation in Scots pine and Norway spruce. Report from Forest Research Institute of Sweden, No. 4 Stockholm, $52 \mathrm{pp}$.

Fletcher, A. M. and R. Faulkner (1972). A plan for the improvement of Sitka spruce by breeding and selection. Forestry Commission Research and Development Paper, No. 85, HMSO, London. 31pp.
FleTCHER, A. M. (1992): Breeding improved Sitka spruce p11-24 In: Super Sitka for the 90s Ed. D. A. Rook, Forestry Commission, Edinburgh, 75pp.

FORESTRY COMMISSION (2003): National Inventory of Woodland and Trees: Great Britain. Forestry Commission, Edinburgh, 58pp.

GILL, J. G. S. (1987): Juvenile-Mature correlations and trends in genetic variances in Sitka spruce in Britain. Silvae Genetica 36(5-6), 189-194.

GILMOUR, A. R. (1996): ASREML, a spatial REML program. Agriculture Research and Veterinary Centre, Orange, New South Wales 2800, Australia, 42pp.

GisLERUD, O. (1973): A wood density study in Norway spruce. In: Proceedings of the IUFRO Joint Working Party, Biri, Norway.

HiLl, W. G. and R. Thompson (1978): Probabilities of nonpositive definite between groups or genetic covariance matrices. Biometrics 34, 429-439.

Hughes, J. F. and R. M. DE Albuquerque Sardinha (1975): The application of optical densitometry in the study of wood structures and properties. Journal of Microscopy 104(1), 91-103.

LEE, S. J. (1999): Improving the timber quality of Sitka spruce through selection and breeding. Forestry $72(2)$, 123-133.

LEE, S. J. (2001): Selection of parents for the Sitka spruce breeding population in Britain and the strategy for the next breeding cycle. Forestry 74(2), 129-143.

LeE, S. J., J. Woolliams, C. J. A. Samuel and D. C. MalCOLM (2002a): A study of population variation and inheritance in Sitka spruce II. Age trends in genetic parameters for vigour traits and optimum selection ages. Silvae Genetica 51 (2-3), 55-65

Lee, S. J., J. Woolliams, C. J. A. Samuel and D. C. MalCOLM (2002b): A study of population variation and inheritance in Sitka spruce III. Age trends in genetic parameters and optimum selection ages for wood density, and genetic correlations with vigour traits. Silvae Genetica 51 (4), 143-151.

Nicholls, J. W. P. and A. G. Brown (1971): The ortetramet relationship in wood characteristics of Pinus radiata. Appita 25(3), 200-209.

PAtTerson, H. D. and R. Thompson (1971): Recovery of interblock information when block sizes are unequal. Biometrika 58, 545-554.

RUDEBJER, P. (1984): Quality and increment of 27-year old Scots pine clones selected based on timber quality. MSc Thesis, Institute of Wood production, University of Umeå, Sweden, 55pp.

SAmuel, C. J. A. and R. C. B Johnstone (1979): A study of population variation and inheritance in Sitka spruce. I. Results of glasshouse, nursery and early forest progeny tests. Silvae Genetica 28(1), 26-32.

Wood, P. E. (1986): Variation and inheritance of wood properties of Sitka spruce. Master of Science Thesis, Oxford Forestry Institute, 97pp.

WorRell, R. (1987): Predicting the productivity of Sitka spruce on upland sites in northern Britain. In: Forestry Commission Bulletin 72, HMSO, London, 12pp.

ZoBel, B. and R. STONECYPHER (1962): Wood properties of clones of slash pine. In: Proceedings of the Forest Genetics Workshop, Southern Forest Tree Improvement Conference, Macon, Georgia.

Herausgeberin: Bundesforschungsanstalt für Forst- und Holzwirtschaft: Schriftleitung: Institut für Forstgenetik und Forstpflanzenzüchtung, Siekerlandstrasse 2, D-22927 Grosshansdorf — Verlag: J. D. Sauerländer's Verlag, Finkenhofstrasse 21, D-60322 Frankfurt a. M. Anzeigenverwaltung: J. D. Sauerländer's Verlag, Frankfurt am Main. Satz und Druck: ADN Offsetdruck, Battenberg — Printed in Germany. 